\title{
Relationship between self-directed learning readiness, learning attitude, and self-efficacy of nursing undergraduates
}

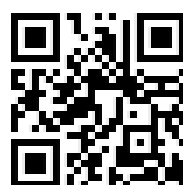

Original article

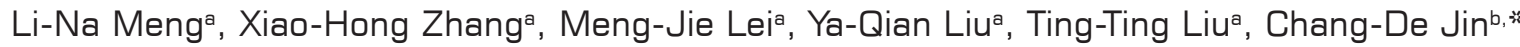

aGraduate Department, Tianjin University of Traditional Chinese Medicine, Tianjin 301617, China

${ }^{b}$ School of Nursing, Tianjin University of Traditional Chinese Medicine, Tianjin 301617, China

Received: 3 April 2018; Accepted: 31 August 2018; Published: 20 December 2019

Abstract: Objective: The purposes of this study were to analyze the influencing factors of self-directed learning readiness (SDLR) of nursing undergraduates and explore the impacts of learning attitude and self-efficacy on nursing undergraduates.

Methods: A total of 500 nursing undergraduates were investigated in Tianjin, with the Chinese version of SDLR scale, learning attitude questionnaire of nursing college students, academic self-efficacy scale, and the general information questionnaire.

Result: The score of SDLR was 149.99 \pm 15.73 . Multiple stepwise regressions indicated that academic self-efficacy, learning attitude, attitudes to major of nursing, and level of learning difficulties were major influential factors and explained $48.1 \%$ of the variance in SDLR of nursing interns.

Conclusions: The score of SDLR of nursing undergraduates is not promising. It is imperative to correct students' learning attitude, improve self-efficacy, and adopt appropriate teaching model to improve SDLR.

Keywords: self-directed learning readiness $\bullet$ nursing undergraduates • learning attitude • academic self-efficacy • relationship

(c) Shanxi Medical Periodical Press.

\section{Introduction}

In recent years, with the development of physiologypsychology-social medical model and the global population of the aged, the demand for nursing staff has risen to a new level. The demand for nursing talents has increased in all walks of life, requiring nurses to meet not only the patient's physical needs but also their psychology, social and other human mental needs. ${ }^{1}$ Currently, five tiers (vocational qualification, associate's degree, bachelor's degree, master's degree, and doctor's degree) coexist in the nursing education system.
The undergraduate nursing model is the major form of nursing education. Chinese nursing education started late. One research, ${ }^{2}$ it was found that the quality of undergraduate nursing education did not match the current social needs or the development of nursing career. Chinese nursing leaders are exploring opportunities to integrate courses, increase humanities courses, and add more new occupation-related courses. The curriculum should focus on "physiology-psychology-social medical model" rather than "disease-focus" model. More courses related to professional value, health care, and evidence-based practice in nursing should be introduced

How to cite this article: Meng LN, Zhang XH, Lei MJ, Liu YQ, Liu TT, Jin CD. Relationship between self-directed learning readiness, learning attitude, and self-efficacy of nursing undergraduates. Front Nurs. 2019; 4: $341-348$. 
into the curriculum, and better study model should be recommended to make an improvement.

Knowles et al. ${ }^{3}$ defined self-directed learning (SDL) as a process in which individuals take the initiative by themselves or with others' help in diagnosing their learning needs, finding their learning goals, identifying all resources for learning, implementing, and finally evaluating learning outcomes. Self-directed learning readiness (SDLR) ${ }^{4}$ refers to the extent to which learners have the necessary conditions for autonomous learning, such as attitudes, abilities, and personality characteristics. $\mathrm{SDLR}^{5}$ is individualized, which accounts for the varying degrees along the continuum.

The concept of self-efficacy was first defined by the American Psychologist Bandura ${ }^{6}$ in 1977. He thinks self-efficacy judgments, whether accurate or faulty, will influence the choice of activities and environmental settings. Academic self-efficacy ${ }^{7}$ is the student's evaluation of the degree of perfection to deal with their own specific academic problems and the possible achievement of corresponding learning activities. According to their self-efficacy, students avoid activities that they believe exceed their coping capabilities, but they undertake and perform assuredly those that they judge themselves capable of.

The influential factors of SDLR and self-efficacy have been deeply analyzed. A study ${ }^{8}$ found that personality factors can influence students' SDLR. A study ${ }^{9}$ found that students' interest and study attitude and study achievements are the influential factors on self-efficacy. However, the relationship between SDLR and academic self-efficacy are not widely applied.

With the rapid development of science and growth of global economy, knowledge has become one of the indicators that regulate economic development. In the clinical nursing field, with the update of nursing skills and knowledge and the growing demand for nursing care by patients, nursing undergraduates relying on what they have learned can no longer meet the needs of social development or succeed in occupational competition. Therefore, undergraduate nursing students must cultivate self-learning ability, correct their learning attitudes, improve their self-efficacy, learn through theoretical studies and practice, and get the ability to adapt to complex environments. While improving their professional qualities, they can improve their competitiveness and adapt to changes in the society as well, so that they could conform to the development of the times. ${ }^{10}$ Students who got a higher level of SDLR managed their time well and their academic achievement was also better. ${ }^{11}$ This study aimed to finding the relationship between SDLR, study attitude, and self-efficacy. Through this study, we suggest undergraduate students to be ready for their SDL, stay positive, and improve their self-efficacy, which will promote their learning ability and get better achievements.

\section{Methods}

\subsection{Study participants}

A total of 500 undergraduate nursing students from fresh to fourth year were enrolled in. The inclusion criteria were students who were (1) able to read and speak Chinese and (2) physically, mentally, and cognitively able to respond to the questionnaires. A research team member provided undergraduates with information about the study. Informed consent was obtained from the students who agreed to participate in the study. A total of 500 questionnaires were distributed, and 429 surveys were included in the data analysis after excluding questionnaires with incomplete data. The recovery rate was $85.8 \%$. The study used a convenient sampling method; a questionnaire survey was conducted on full-time undergraduate nursing students in Tianjin.

\subsection{General information}

The research team adopted a self-report method based on the literature review and mainly included four parts: (1) General demographic variables including gender, grade, done part-time job and Living area (2) Whether the undergraduates' first choice is apply for nursing majors or not and they have done part-time job, etc, adopt "Yes" or "No" as an answer. (3) How much they like the nursing profession and the difficulties in learning under the curriculum are measured using the Likert four-level scoring method. (4) self-study status Satisfaction adopts seven-category level options, such as very dissatisfied, dissatisfied, little bit unsatisfied, uncertain, a little satisfied, satisfied, and very satisfied.

\subsection{Self-directed learning readiness scale (SDLRS) for nursing education}

Fisher et al. ${ }^{12}$ developed the SDLRS for nursing education. The Delphi technique with a panel of 11 nurse educator experts was used to assess the construct and content validity of a number of items perceived to reflect SDLR. In all, 201 undergraduate nursing students were involved in the administration of the questionnaire to develop the SDL. Cronbach's $\alpha$ value was 0.830-0.924. The SDLR was translated and validated in China by Wang ${ }^{13}$ The SDLR including a total of 40 items with three dimensions (self-management, love of learning, and self-control) had a high reliability and validity. The total Cronbach's $\alpha$ value was 0.932 . A scoring method used the Likert 5-point scale. Scores from 1 to 5 
indicated that they strongly disagreed to strongly agree. The higher the score, the better the self-study preparation of nursing undergraduates.

\subsection{Learning attitudes}

These surveys were conducted using the learning attitude questionnaire for advanced nurse students, which was compiled by the domestic scholar Zhang. ${ }^{14}$ The questionnaire consisted of four dimensions: learning interest, learning experience, personal learning habits, and understanding of nursing profession. It comprised 23 items. Likert 5-point scale was used (1 = strongly agree, 2 = agree, 3 = neutral, $4=$ disagree, and $5=$ strongly disagree). The higher the score, the better the student's attitude toward learning. The questionnaire was of great reliability and validity; the total Cronbach's $\alpha$ value was 0.927 .

\subsection{Academic self-efficacy}

The academic self-efficacy questionnaire has been compiled by Liang..$^{15}$ The questionnaire consisted of two subscales, learning ability self-efficacy with 11 items and learning behavior self-efficacy with 11 items. There were 22 items in total that used Likert 5-point scale ( 5 = strongly agree, 4 = agree, $3=$ neutral, 2 = disagree, and 1 = strongly disagree). The sum of the two dimensions was the total academic self-efficacy. The higher the score, the higher the sense of efficacy; Cronbach's $\alpha$ value was $0.752-0.820$. In this study, the Cronbach's $\alpha$ of self-efficacy questionnaire was 0.815 .

\subsection{Study design}

The objectives of our study design were to (1) find the nursing undergraduates' differences among diverse demographic characteristics; (2) find the nursing undergraduates' SDLR current status; (3) perform correlation analysis of learning attitude, academic self-efficacy, and SDLR; (4) carry out analysis of the factors influencing on nursing undergraduates' SDLR; and (5) accomplish regression analysis of influencing factors on self-study readiness of nursing undergraduates.

\subsection{Statistical methods}

The collected questionnaires were manually screened and checked to reject those that are incomplete. The data were analyzed using SPSS 21.0 software for statistical analysis. To describe the sample characteristics, descriptive statistics, particularly mean, standard deviation for continuous variables, frequency, and percentage for dichotomous variables, were used. Students in different situations were assessed using the $t$-test or analysis of variance to see if there were significant differences in SDLRS scores; correlation analysis was used to explore the relationship between learning state, academic self-efficacy, and self-directed study readiness. To explore the influencing factors of the self-study preparation of nursing students, we took self-study preparation as the dependent variable, general information of nursing undergraduates, learning attitudes and academic self-efficacy as independent variables, a stepwise regression analysis was conducted. $P<0.05$ indicates a statistically significant difference.

\section{Results}

\subsection{General information analysis of nursing undergraduates}

Of the 429 nursing students, 50 were boys and 379 were girls. The average age of the students was $21.28 \pm 1.49$ years. The proportions of all grades were as follows: 105 freshman nursing students, accounting for $24.5 \%$; 105 sophomore nursing students, accounting for $24.5 \%$; 132 junior nursing students, accounting for $30.8 \%$; and 87 senior nursing students, accounting for $20.3 \%$. Among the 429 nursing students, $347(80.9 \%)$ have done parttime work before, 208 (48.5\%) were from rural areas, and $222(51.7 \%)$ did not apply nursing major as their first choice. In all, $47.1 \%$ students chose to prefer their major, while $5.4 \%$ students hated care professionals. A total of 265 cases (accounting for $61.8 \%$ ) were satisfied with the current teaching style, while $1.9 \%$ expressed dissatisfaction. In all, $30.5 \%$ of the nursing students were unsatisfied with their current learning situation, while $63.2 \%$ of the nursing students had no learning difficulties.

\subsection{Nursing undergraduates' SDLR current status}

The results showed that the SDLR score was $149.99 \pm 15.73$, which was at a moderate level. The results are shown in Table 1.

\begin{tabular}{lccc}
\hline Dimensions score & Maximum & Minimum & Score $(M \pm S D)$ \\
\hline \hline Self-management & 65.00 & 16.00 & $44.79 \pm 6.56$ \\
Desire for learning & 60.00 & 28.00 & $47.38 \pm 5.41$ \\
Self-control & 36.00 & 75.00 & $57.81 \pm 6.32$ \\
Self-learning total score & 200.00 & 93.00 & $149.99 \pm 15.73$ \\
\hline
\end{tabular}

Note: SDLRS: self-directed learning readiness scale; SD: standard deviation.

Table 1. Nursing undergraduates' SDLRS and each dimension score 


\subsection{Correlation analysis of learning attitude, academic self-efficacy, and SDLR $(r)$}

According to SPSS statistics, the total score of learning attitude is $73.99 \pm 11.92$ and the total score of academic self-efficacy is $76.26 \pm 8.17$. In order to further understand the relationship between learning attitude, academic self-efficacy, and the SDLR, the analysis of their correlation is shown in Table 2.

Results showed that the preparation degree of independent learning ability of nursing undergraduates is significantly correlated with three main variables including earning interest, learning experience, learning habit and nursing specialty, and it has a significant correlation with learning ability self-efficacy and learning behavior self-efficacy. Overall, there is a significant correlation between the degree of SDLR, learning attitude of nursing undergraduates, and academic self-efficacy.

\subsection{Analysis of the factors influencing on nursing undergraduates' SDLR}

Single-factor variance analysis of nursing undergraduates' self-study readiness take the SDLR as the dependent variable, with gender, age, grade, part-time job, living area, the first choice to apply for collage major, attitude toward nursing professional, teaching style satisfaction, learning status satisfaction, learning difficulty as the independent variable, we conduct a single-factor variance analysis. The results show that the statistical difference between grade, living area, love the nursing profession, the teaching style satisfaction, the study satisfaction, and the class study difficulty is significant $(P<0.05)$ and the statistical difference among the rest of the variables is not significant $(P>0.05$; Table 3$)$.

\subsection{Regression analysis of influencing factors on self-study readiness of nursing undergraduates}

Taking the total score of self-directed readiness as the dependent variable, the six variables of single-factor analysis and learning attitude and academic self-efficacy were used as independent variables to enter the stepwise regression equation. The standard was 0.05 , and the level of elimination was 0.10 . The results showed that the factors that influenced the degree of self-study readiness of nursing undergraduates were as follows: academic self-efficacy, learning attitude, liking nursing major, and learning difficulty after class. The value of $F=98.35(P=0.000)$ indicates that the regression equation is statistically significant. The cumulative variance of the four variables for autonomic learning readiness was $48.1 \%$ (Table 4 ).

\section{Discussion}

\subsection{Nursing undergraduates' SDLR status}

The study of Kar et al. ${ }^{16}$ found that the independent study readiness score could indicate that the students have the good independent study ability only when they got at least 150 marks or higher. In this study, the total score of the undergraduates' independent learning readiness

\begin{tabular}{|c|c|c|c|c|c|c|c|c|c|c|c|c|}
\hline Items & A & B & C & D & $E$ & $\mathrm{~F}$ & $\mathrm{G}$ & $\mathrm{H}$ & 1 & $J$ & $\mathrm{~K}$ & $\mathrm{~L}$ \\
\hline$A$ & 1 & & & & & & & & & & & \\
\hline$B$ & $0.537^{*}$ & 1 & & & & & & & & & & \\
\hline C & $0.616^{\star}$ & $0.673^{*}$ & 1 & & & & & & & & & \\
\hline$D$ & $0.849^{*}$ & $0.838^{*}$ & $0.890^{*}$ & 1 & & & & & & & & \\
\hline$E$ & $0.213^{*}$ & $0.127^{\star}$ & $0.144^{*}$ & $0.190^{\star}$ & 1 & & & & & & & \\
\hline $\mathrm{F}$ & $0.256^{\star}$ & $0.414^{*}$ & $0.318^{*}$ & $0.377^{\star}$ & $0.526^{*}$ & 1 & & & & & & \\
\hline G & $0.510^{*}$ & $0.348^{*}$ & $0.410^{*}$ & $0.497^{\star}$ & $0.462^{\star}$ & $0.505^{\star}$ & 1 & & & & & \\
\hline$H$ & $0.196^{\star}$ & $0.256^{\star}$ & $0.148^{*}$ & $0.299^{*}$ & -0.004 & $0.263^{*}$ & $0.126^{\star}$ & 1 & & & & \\
\hline 1 & $0.428^{*}$ & $0.401^{*}$ & $0.377^{*}$ & $0.466^{\star}$ & $0.753^{*}$ & $0.830^{*}$ & $0.795^{\star}$ & $0.382^{*}$ & 1 & & & \\
\hline$J$ & $0.507^{*}$ & $0.431^{*}$ & $0.540^{\star}$ & $0.576^{\star}$ & $0.309^{*}$ & $0.314^{*}$ & $0.484^{*}$ & 0.018 & $0.432^{*}$ & 1 & & \\
\hline K & $0.557^{\star}$ & $0.490^{*}$ & $0.509^{*}$ & $0.606^{*}$ & $0.138^{*}$ & $0.288^{*}$ & $0.396^{*}$ & $0.288^{*}$ & $0.372^{*}$ & $0.621^{*}$ & 1 & \\
\hline L & $0.591^{*}$ & $0.512^{*}$ & $0.582^{*}$ & $0.657^{*}$ & $0.247^{\star}$ & $0.334^{*}$ & $0.488^{*}$ & $0.138 *$ & $0.446^{\star}$ & $0.898^{\star}$ & $0.903^{*}$ & 1 \\
\hline
\end{tabular}

Note: ${ }^{\star} P<0.01$. SDLR: self-directed learning readiness; A: self-management; B: desire for learning; C: self-control; $D$ : self-directed total score; E: study interest; F: study experience; G: study habit; H: knowledge of nursing profession; I: total attitude; J: ability self-efficacy; K: behavioral self-efficacy; L: efficiency total sore.

Table 2. Correlation analysis of learning attitude, academic self-efficacy, and SDLR of nursing undergraduate's $r$. 


\begin{tabular}{|c|c|c|c|}
\hline Item & Number (n) & Score $(M \pm S D)$ & $t / F$ \\
\hline Gender & & & 1.538 \\
\hline Male & 50 & $153.19 \pm 19.07$ & \\
\hline Female & 379 & $149.56 \pm 15.22$ & \\
\hline Grade & & & $5.473^{*}$ \\
\hline First grade & 105 & $149.04 \pm 14.27$ & \\
\hline Second grade & 105 & $153.99 \pm 13.31$ & \\
\hline Third grade & 132 & $150.76 \pm 17.38$ & \\
\hline Fourth grade & 87 & $145.09 \pm 16.30$ & \\
\hline Done part-time job & & & 1.154 \\
\hline Yes & 347 & $150.41 \pm 15.74$ & \\
\hline No & 82 & $148.18 \pm 15.67$ & \\
\hline Living area & & & $3.67^{* \star}$ \\
\hline City & 103 & $153.07 \pm 15.02$ & \\
\hline Suburbs and towns & 118 & $147.35 \pm 17.15$ & \\
\hline Rural area & 208 & $149.95 \pm 15.02$ & \\
\hline $\begin{array}{l}\text { Apply nursing major as first } \\
\text { college choice }\end{array}$ & & & -1.585 \\
\hline Yes & 207 & $148.74 \pm 15.44$ & \\
\hline No & 222 & $151.14 \pm 15.95$ & \\
\hline Study satisfaction & & & $5.297^{\star}$ \\
\hline Very unsatisfied & 12 & $158.00 \pm 15.01$ & \\
\hline Unsatisfied & 93 & $146.83 \pm 15.89$ & \\
\hline Little bit unsatisfied & 131 & $148.75 \pm 14.83$ & \\
\hline Not sure & 48 & $145.26 \pm 13.52$ & \\
\hline Little bit satisfied & 114 & $152.48 \pm 14.83$ & \\
\hline Satisfied & 24 & $158.63 \pm 16.80$ & \\
\hline Very satisfied & 7 & $177.41 \pm 26.26$ & \\
\hline Love nursing major & & & $4.075^{\star}$ \\
\hline Like very much & 19 & $158.47 \pm 23.16$ & \\
\hline Like & 202 & $151.55 \pm 14.33$ & \\
\hline Do not feel & 185 & $147.69 \pm 16.05$ & \\
\hline Hate & 23 & $147.65 \pm 14.58$ & \\
\hline Teaching style & & & $10.643^{*}$ \\
\hline Very satisfied & 17 & $168.94 \pm 19.07$ & \\
\hline Satisfied & 265 & $150.67 \pm 15.56$ & \\
\hline Not sure & 80 & $143.86 \pm 13.02$ & \\
\hline Unsatisfied & 59 & $148.81 \pm 13.31$ & \\
\hline Very unsatisfied & 8 & $156.63 \pm 20.23$ & \\
\hline Difficulties after class & & & $10.971^{\star}$ \\
\hline No difficulties & 17 & $159.80 \pm 25.28$ & \\
\hline Almost no difficulties & 271 & $152.60 \pm 14.47$ & \\
\hline Have difficulties & 130 & $144.49 \pm 13.69$ & \\
\hline Large difficulties & 11 & $138.00 \pm 25.92$ & \\
\hline
\end{tabular}

Note: ${ }^{\star} P<0.01 ;{ }^{*} P<0.05$. SDLRS: self-directed learning readiness scale; SD: standard deviation.

Table 3. Analysis of variance of SDLRS single factors in nursing undergraduates $(N=429)$

degree was $149.99 \pm 15.73 ; 25.4 \%$ of the nursing undergraduates $(n=109)$ got higher than 150 marks, which indicated that most of the nursing undergraduates had

\begin{tabular}{lrcrc}
\hline Factors & $B$ value & $B$ value & \multicolumn{1}{c}{$T$} & $P$ \\
\hline \hline Constant & 45.568 & - & 5.874 & 0.000 \\
Self-efficiency & 1.033 & 0.536 & 13.238 & 0.000 \\
Study attitude & 0.342 & 0.259 & 5.984 & 0.000 \\
Prefer nursing major & 2.299 & 0.098 & 2.451 & 0.015 \\
Study difficulties after class & -2.382 & -0.084 & -2.274 & 0.023 \\
\hline
\end{tabular}

Note: $F=98.35, P=0.000, R=0.694$, and $R^{2}=0.481$. SDLRS: self-directed learning readiness scale.

Table 4. Regression analysis of SDRLS-related factors in nursing undergraduates

poor self-direct learning ability. In addition, the highest scoring dimension was self-control, while the lowest scoring dimension was self-management, which shows that the current nursing undergraduates have a good sense of responsibility and they can set the learning goal and evaluation standard independently. As far as the results of poor self-management and lack of selflearning ability are considered, they match the research results of Alharbi. ${ }^{17}$ Therefore, in the process of improving the readiness of nursing undergraduates' self-direct learning readiness, the cultivation of self-management ability should be strengthened.

\subsection{Factors influencing the self-study readiness of nursing undergraduates}

The results show that the demographic characteristics including grade, living area, love the nursing profession, the teaching style satisfaction, the study satisfaction and the class study difficulty have a statistical significant difference $(P<0.05)$; however, because of some options as the sample was too small in the "study satisfaction" and "teaching style" items, we should explain the results more cautiously. The statistically significant difference between the gender, whether done a part-time job, and apply nursing major as first college choice is not significant $(P>0.05)$. After regression analysis, this study concluded that the degree of self-study ability of nursing undergraduates has academic self-efficacy, learning attitude, prefer nursing major, learning difficulties under four factors, each factor analysis is as follows:

Academic self-efficacy can reflect the individual's judgment and self-confidence in completing academic tasks. ${ }^{18}$ In this study, the results show that academic self-efficacy is positively correlated with the preparation degree of SDL, and the higher the self-efficacy, the more obvious the characteristics of SDL ability, such as good control of emotion, cognitive strategy, and reasonable choice. This result is consistent with the research results of Zhang et al. ${ }^{19}$. In short, the improvement of 
self-efficacy is beneficial to the improvement of SDL ability. According to the statistical analysis, the total academic self-efficacy of nursing undergraduates is $76.26 \pm 8.17$, which indicates that nursing undergraduates can make study plans, study actively, and have confidence in completing their own studies.

Back in the 1960s, De Montlibert et al. ${ }^{20}$ first defined learning attitude as the degree that consists of three dimensions of cognition, emotion, and behavioral intention. Liu and Peng ${ }^{21}$ believed that learning attitude refers to the psychological tendency of learners to respond to learning activities from three aspects of cognition, emotion, and behavior, including 22 attitudes towards learning, teachers, and schools. The survey of Wang, ${ }^{23}$ Wang, ${ }^{24}$ and Malekian et al. ${ }^{25}$ all showed the learning attitude as an intrinsic factor that significantly affects students' autonomous learning. This study also shows that the learning attitude is positively correlated with the readiness of SDL, that is, the better the learning attitude, the higher the readiness of SDL. Students with a high interest in learning can actively learn knowledge and skills, and constantly improve themselves, which is an important ability to improve independent learning. One study ${ }^{26}$ showed that university student's independent study ability is not very positive in China at present; therefore, instructions for students to correct their study attitude are urgent and necessary. In this way, students could promote their independent self-directed study readiness, stay active, and have a high efficiency, which must benefit both their study and research.

This research showed that the study desire of nursing students is one of the factors influencing the SDLR, which is consistent with previous studies. ${ }^{15}$ However, $48.5 \%$ of nursing undergraduates' attitude toward nursing profession had not reached the level of preference yet, which is similar to previous research results. ${ }^{27}$ Studies have shown that the higher the students' preference for the professional knowledge of nursing, the stronger their initiative and self-confidence. The improvement of their SDLR will promote their recognition of the nursing profession. ${ }^{28}$ Before students make the choice of their major, they will consider about their interest first; their inner interest will become a subconscious to motivate their study. Therefore, in the course of training nursing undergraduates' professional knowledge, the nursing educators can improve their SDL ability by improving their specialty identification.

In this study, learning difficulties under class have a negative impact on SDL. The traditional teaching model makes students more dependent on acquiring knowledge from teachers, while the ability to solve problems under class decreases. Leatemia et al. ${ }^{29}$ believe that the teacher-centered traditional teaching mode makes the students' thinking limited, which is one of the factors that lead to the students' poor SDL ability. Therefore, the teaching mode should shift from teacher centered to student centered and cultivate the ability of problemsolving of nursing students to find their own way of learning. At the same time, the nursing educators should fully understand the students' learning characteristics and adopt the interactive teaching and Problem-Based Learning (PBL) teaching mode ${ }^{30}$ to improve their interest in learning and to cultivate the ability of nursing students to solve problems. In the class, supervision and group discussion are adopted to guide and regulate SDL and promote common progress..$^{31,32}$

\section{Conclusions}

The study showed that the degree of SDLR of nursing undergraduates was low, and it was influenced by academic self-efficacy, learning attitude, desire for learning nursing specialty, and learning difficulty degree. It can improve the self-learning ability of nursing undergraduates from improving self-efficacy, instructing students to correct their learning attitude, improving their professional identity and cultivating their ability of solving problems. With the renewal of nursing knowledge and skills, nursing educators should pay attention to students' SDL ability to adapt to social changes and improve their social competitiveness.

\section{Limitations}

There are many factors that affect the degree of selfstudy readiness of nursing undergraduates, and the aim of this study was to explore the influence of learning attitude and academic self-efficacy on autonomic learning readiness, so many influencing factors are not widely involved.

Second, this research is limited to Tianjin, with regional limitations, and the sample size is relatively small; longer follow-up should be applied in further studies.

\section{Acknowledgment}

The authors are greatly thankful to all the undergraduate nursing participants for their contribution to this study.

\section{Ethics approval}

This study was approved by Research Ethics Committee of Tianjin University of Traditional Chinese Medicine. Students were informed about the research procedure 
and purpose of this study. We also made sure that students are willing to participate and there are no negative effects on their final sore or other experience.

\section{References}

1. Wang YX. Li HP, Ding XT, Xiao T, Jiang XX, Zhang MM. Advances in nursing education resources. J Nurs Sci. 2017;32:107-110 (in Chinese).

2. Wang Chunfeng $C$. Closing the gap in nursing education: comparing nursing registration systems in Australia and China. Chin Nurs Res. 2016;3:1-6.

3. Knowles MS, Holton EF, Swanson RA. The adult learner. The definitive classic on adult education and human resource development. Ind Commer Training. 2005;45:107-109.

4. Fisher MJ, King J. The self-directed learning readiness scale for nursing education revisited: a confirmatory factor analysis. Nurse Educ Today. 2010;30:44-48.

5. Premkumar K, Vinod E, Sathishkumar S, et al. Self-directed learning readiness of Indian medical students: a mixed method study. BMC Med Educ. 2018;18:134.

6. Bandura A, Adams NE. Analysis of self-efficacy theory of behavioral change. Cognit Ther Res. 1977;1:287-310.

7. Schunk DH, Pajares F. The development of academic self-efficacy. In: Wigfield A, Eccles JS, eds. Development of Achievement Motivation. Chap 1. San Diego, CA, US: Academic Press; 2002:15-31.

8. Slater CE, Cusick A, Louie JCY. Explaining variance in self-directed learning readiness of first year students in health professional programs. BMC Med Educ. 2017;17:207.

9. Kapucu S. Predicting physics achievement: attitude towards physics, self-efficacy of learning physics, and mathematics achievement. Asia-Pacific Forum Sci Learn Teach. 2017;18:113-116.

10. Wu DF. Study on Self-Directed Learning Ability and its Influencing Factors among Nursing Undergraduates. Central South University; 2014 (in Chinese).

11. Ertu $\square$ N, Faydali S. Investigating the relationship between self-directed learning readiness and time management skills in Turkish undergraduate nursing students. Nurs Educ Perspect. 2018;39:E2-E5.

12. Fisher M, King J, Tague G. Development of a selfdirected learning readiness scale for nursing education. Nurs Educ Today. 2001;21:516-522.

13. Wang W. Investigation of Nursing Students' SelfDirected Learning Ability and Problem-Solving Ability. Fudan University; 2010 (in Chinese).

\section{Conflicts of interest}

All contributing authors declare no conflicts of interest.

14. Zhang $\mathrm{YH}$. An Investigation on Undergraduates Nursing Students' Attitude Toward Study and Influencing Factors. Huazhong University of Science and Technology; 2011 (in Chinese).

15. Liang SY. Study on Achievement Goals, Attribution Styles and Academic Self-Efficacy of College Students. Central China Normal University; 2000:32 (in Chinese).

16. Kar SS, Premarajan KC, Ramalingam A, Iswarya S, Sujiv A, Subitha L. Self-directed learning readiness among fifth semester MBBS students in a teaching institution of South India. Educ Health (Abingdon). 2014;27:289-292.

17. Alharbi HA. Readiness for self-directed learning: how bridging and traditional nursing students differs? Nurse Educ Today. 2018;61:231-234.

18. Liao J, Ni P. Investigation on status and influencing factors of self-directed learning readiness in nursing undergraduates School of Nursing. J Nurs Sci. 2017;32:55-58 (in Chinese).

19. Zhang DQ. Study on the Relationship Between Self-Regulated Learning Perceived Self-Efficacy and Academic Emotion of Medical Students. Shanxi Medical University; 2016 (in Chinese).

20. De Montlibert $C$, Pagès $R$, Rosenberg $M$, et al. Attitude organization and change: an analysis of consistency among attitude components. Revue Française de Sociologie. 1961;2:333-334.

21. Liu HJ, Peng XY. The relationship between academic self-efficacy and learning attitude of college students. Sci Soc Psych. 2016;1:24-31 (in Chinese).

22. Zhang F. The Research on Affect of College Students' Learning Attitudes. Xi'an Technological University; 2014 (in Chinese).

23. Wang T. Research on the Status Quo of the College Students' Self-Directed Learning and it's Influencing Factors. Northeast Normal University; 2014 (in Chinese).

24. Wang S. Research of Undergraduate Students Autonomous Learning Status and Influence Factors. Nanchang University;2016:53 (in Chinese).

25. Malekian M, Ghiyasvandian S, Cheraghi MA, Hassanzadeh A. Iranian clinical nurses' readiness for self-directed learning. Glob J Health Sci. 2015;8:157-164. 
26. Wang J, Zou JY, Lin J. Effect research of smartphone-based mobile learning on autonomous learning ability of higher vocational students. Chin Nurs Res. 2018;32:1451-1453 (in Chinese).

27. Wang XJ, Yu JZ, Yang HY. Research on current situation and influencing factors of professional commitment of nursing undergraduates. J Nurs (China). 2016;23:42-45 (in Chinese).

28. Xu XY, Xu HB, Zhao P, Zhou LS, Wag YL, Li M. Study on the relationship between professional identity and academic self-efficacy of nursing students with different academic degrees. J Nurs Sci. 2014;29:61-63 (in Chinese).

29. Leatemia LD, Susilo AP, van Berkel H. Self-directed learning readiness of Asian students: students perspective on a hybrid problem based learning curriculum. Int J Med Educ. 2016;7:385-392.

30. Gan JH, Qiu SP, Fan QM, Liu L, Wang F, Lan GY. Application research of $\mathrm{PBL}$ and $\mathrm{LBL}$ teaching method in ophthalmology nursing course of higher vocational nursing specialty. J Nurses Training. 2018;33:89-92 (in Chinese).

31. Lestari E, Stalmeijer RE, Widyandana D, Scherpbier A. Understanding students' readiness for interprofessional learning in an Asian context: a mixed-methods study. BMC Med Educ. 2016; 16:179.

32. Montenery S. Problem-based learning for didactic presentation to baccalaureate nursing students. Creat Nurs. 2017;23:102-111. 